\title{
Gas Turbine Performance Optimization Using Compressor Online Water Washing Technique
}

\author{
Ezenwa Alfred Ogbonnaya \\ Department of Marine Engineering Rivers State University of Science and Technology, \\ Nkpolu, Port Harcourt, Nigeria \\ E-mail: ezenwaogbonnaya@yahoo.com \\ Received February 10, 2011; revised March 22, 2011; accepted April 6, 2011
}

\begin{abstract}
The ability to predict the behaviour of a gas turbine engine and optimize its performance is critical in economic, thermal and condition monitoring studies. Having identified fouling as one of the major sources of compressor and therefore gas turbine deterioration, a computer-based engine model was developed to optimize the performance of gas turbines. The paper thus presents an analysis of compressor hand cleaning, on and offline compressor washing to actualize the technique using a computer program in Visual Basic programming language with data collected over a period of fifteen weeks for 2 gas turbine plants GT1 and GT2. The results of the data collected, when collated, shows that after washing, the overall operational efficiency changed from $39.2 \%$ to $46.25 \%$. To optimize the performance of gas turbine engines, it is therefore recommended that operators should perform a combination of compressor hand cleaning, offline and online washing simultaneously.
\end{abstract}

Keywords: Gas Turbine, Turbomachinery Components, Fouling, Performance Optimization, Operational Practices, Compressor Water Washing

\section{Introduction}

Gas Turbines (GTs) have wide range of industrial applications. Proper maintenance and operating practices can significantly affect the level of performance degradation and thus time between repairs or overhauls of a GT [1-5]. The correct construction and operation of the components of GT plants are also necessary for proper understanding and monitoring. Furthermore, the function of a GT is the result of the fine-tuned cooperation of many different components of the plant. [6-9]. The emphasis of this work is on the turbomachinery or aerodynamic components of the GT. Hence the special contribution of this work to GT operation and maintenance is that it helps to prolong the life of the turbomachinery components of the engine.

From the point of view of application, the GT's compressor is affected by the environmental conditions of the site [10-12]. With increasing operating time, degradation of the compressor manifest in the form of reduced performance. The major cause of reduction in compressor efficiency and inlet air mass flow is fouling. Others are abrasion, corrosion and erosion of the blade surfaces.
The degradations of the GT compressor has direct influence on the GT power plant efficiency, pressure ratio and power. With a view to prevent degradation, optimize performance and increase availability, GTs are equipped with sophisticated air filter systems. These air filter systems significantly reduce the amount of contaminants that GTs are subjected to but cannot filter out the contaminant completely [11]. This present work applied online water washing to optimize the performance of a GT plant on industrial duty for electricity generation in Sapele, Delta State of Nigeria. It further looked into the plus and minus of other GTs maintenance techniques.

Operation of a GT at steady outputs can lead to deposition from the combustion gas on the blades. Deposits cause output and efficiency to drop by reducing the efficiency of energy transfer and eventually restricting the flow of the combustion gases $[5,13]$. There are quite a number of wear out problems associated with GT. The blades may break off or corrode, while bearings may wear out due to friction and vibration. Common faults on the rotor include rubbing, temporary unbalance, eccentricity cracking or/and misalignment [10]. The compressor may experience air leakage problems while 
deposits on the blades can create blade washing effects [14]. Performance analysis can be applied to both rotating and stationary parts of the GT. It is one condition monitoring technique which allows the optimum time for restorative maintenance to be calculated, where the deterioration may result in increased fuel consumption or in reduced output or both [15-21]. The types of compressor cleaning methods with their merits and demerits are detailed as follows:

\subsection{Compressor Abrasive Cleaning}

The application of abrasive materials for cleaning of compressors such as the injection of rive or walnutshell into the compressor for its clearing is becoming outdated $[11,22,23]$. This is because the erosion impact is more followed by the danger that these non-liquid materials are capable of clogging the passages of the seconddary air system. Furthermore, these non-liquid particles may cause damage to the compressor blade coating.

\subsection{Compressor Hand Cleaning}

This entails cleaning the inlet guide vanes (IGV) and the blades of the first compressor row with brushes and a detergent [24]. Although this method is effective for removing particles sticking to the blade surface, its shortcoming is that it is time consuming and requires the GTs to be shutdown. Hence this method should be supported by offline washing.

\subsection{Compressor Offline Washing}

In this method, the GT has to be shutdown and cooled, followed by flushing the compressor with demineralized water [24]. This approach enables compressor fouling to be removed virtually completely. With a view to avoid GTs non-availability, this method should be used during normal inspection interval.

\subsection{Compressor Online Washing}

This technique is normally done during GTs base-load operation with the IGVs in the fully open condition. It is achieved by installing an online washing system at the air inlet of the GTs [25,11]. Although this method is known to diminish compressor fouling, it can not completely eliminate it.

\section{Methodology}

The test engines are GTs 1 and 2 of the same capacity (45 MW) on industrial duty for electricity generation in
Sapele, Delta State of Nigeria. Both GTs were commissioned on the same day. After a period of three month GT1 and GT2 were shutdown for maintenance. The online washing method was done on weekly intervals for a period of fifteen weeks. Deminerialized water was injected through a configuration of small nozzles in the air flow before the first compressor stage. At the end of the exercise, the data gathered from both plants on daily basis were sampled and the mean used in this research. These parameters enabled the calculation of the compressor efficiency and other relevant operational parameters. In this work, it was assumed that the compressor inlet conditions correspond to the ambient conditions.

The analyses were performed with the equations below, while the experimental setup is shown in Figure 1. Figure 2 also shows the enthalphy versus entropy map of a compressor. It is between 2 and 2' that water washing takes place. Therefore $H_{2}^{\prime}$ is the enthalpy after water washing.

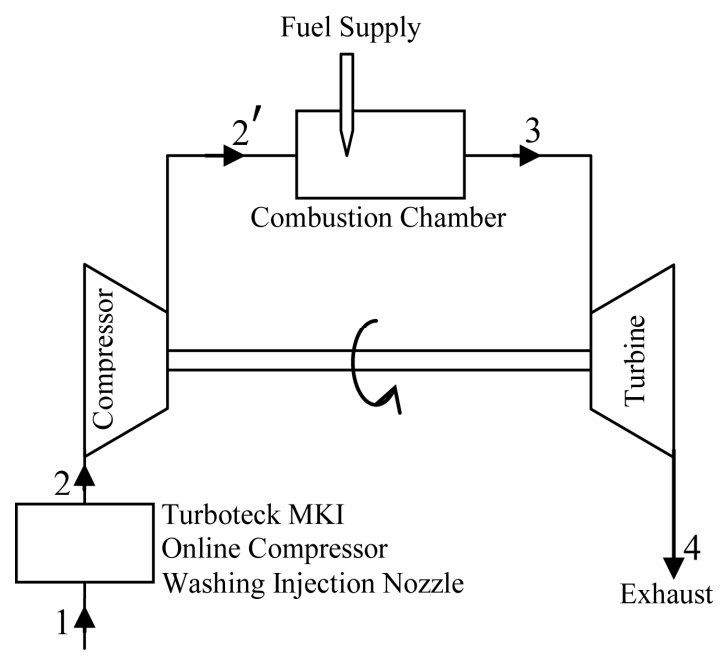

Figure 1. Experimental setup for GTs 1 and 2.

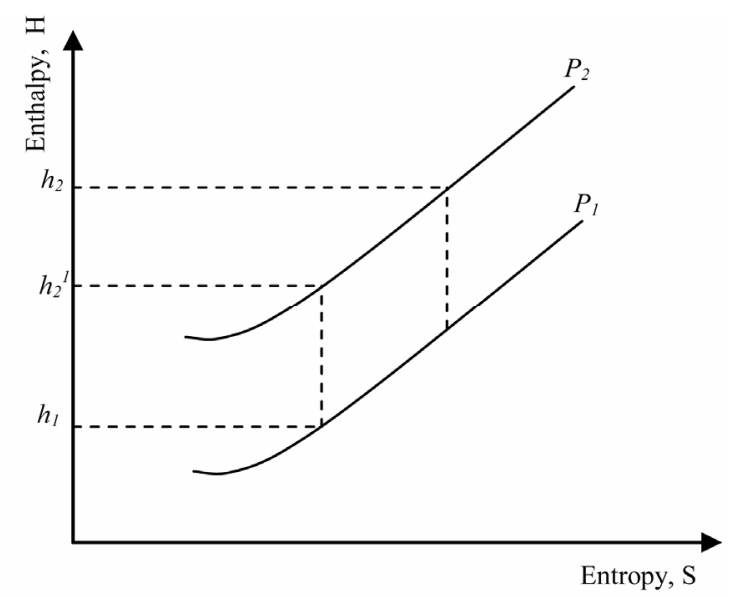

Figure 2. Enthalpy versus entrophy map of compression [11]. 
The compressor component is modeled as:

$$
\frac{T_{2}^{\prime}}{T_{1}}=\left(\frac{P_{2}}{P_{1}}\right)^{\frac{\gamma-1}{\gamma}}
$$

Similarly, the turbine component is expressed as:

$$
\frac{T_{3}}{T_{4}^{\prime}}=\left(\frac{P_{3}}{P_{4}}\right)^{\frac{\gamma-1}{\gamma}}
$$

Furthermore, the isentropic efficiency of the compressor is expressed as;

$$
\begin{gathered}
\eta_{c}=\frac{\text { Isentropic enthalphy drop }}{\text { Actual enthalpy drop }} \\
\eta_{c}=\frac{h_{2}^{\prime}-h_{1}}{h_{2}-h_{1}}
\end{gathered}
$$

Also, the isentropic efficiency of the turbine is given by:

$$
\begin{gathered}
\eta_{T}=\frac{\text { Actual enthalphy drop }}{\text { Isentropic enthalpy drop }} \\
\eta_{T}=\frac{T_{3}-T_{4}}{T_{3}-T_{4}^{\prime}}
\end{gathered}
$$

The compressor work is modeled as:

$$
W_{c}=-\left[h_{2}-h_{1}\right]
$$

Since, $\mathrm{dh}=$ Cpdt,

$$
W_{c}=-C_{p}\left[T_{2}-T_{1}\right]
$$

The turbine work is modeled as:

$$
\begin{aligned}
W_{T}=-\left[h_{4}-h_{3}\right] \\
\Rightarrow W_{T}=-C_{p}\left[T_{4}-T_{3}\right]
\end{aligned}
$$

The heat input is expressed as:

$$
\begin{gathered}
Q_{i n}=h_{3}-h_{2} \\
\Rightarrow Q_{i n}=C_{p}\left[T_{3}-T_{2}\right]
\end{gathered}
$$

Similarly, the heat output is given by:

$$
\begin{aligned}
Q_{\text {out }} & =\left[h_{1}-h_{4}\right] \\
\Rightarrow Q_{\text {out }} & =C_{p}\left[T_{1}-T_{4}\right]
\end{aligned}
$$

The Network output and heat input is expressed respectively as:

$$
\begin{aligned}
& \sum W=W_{c}+W_{T} \\
& \sum Q=Q_{\text {in }}+Q_{\text {out }}
\end{aligned}
$$

The overall efficiency of the test engine is modeled as:

$$
\begin{gathered}
\eta_{t h}=\frac{\text { Net } \text { work }}{\text { Net Heat Supplied }} \\
\therefore \eta_{t h}=\frac{W_{T}-W_{c}}{Q_{i n}}
\end{gathered}
$$

By appropriate substitutions,

$$
\eta_{t h}=1-\left(\frac{1}{\gamma_{p}}\right)^{\frac{\gamma-1}{\gamma}}
$$

Noting that $\gamma_{p}$ is called the pressure ratio and is expressed as:

$$
\gamma_{p}=\frac{P_{2}}{P_{1}}=\frac{P_{3}}{P_{4}}
$$

\section{Results}

The results of the analyses carried out on GT 1, and GT2 are shown in Tables $\mathbf{1}$ and 2. Table 2 shows the data taken before water washing. Table 3 shows the monitored data for GT2 during the combination of the 3 water washing methods considered in this work while Table 4 shows the values of percentage derivations in outlet parameter. The values in these tables were used to plot the various graphs shown from Figures 5 to 9. These graphs are further used to explain the impact of this work to engineering pratise. Figure 3 shows a programme flowchart to determine the performance of the GTs. The flowchart was constructed from Equations 6, 8 and 17.

\section{Discussion of Results}

The trajectories of the GTs when the compressor outlet pressure is plotted against date in weeks are shown in Figure 4. It shows that before the washing exercise, the plants were operating at $7.00 \mathrm{bar}$, as depicted in trend for GT1. The compressor outlet pressure is an indication of fouling, as this menace causes a reduction of the pressure. Following the application of water washing to GT1, it was observed that the pressure increased to 7.88 bar. These pressures were maintained by the regular weekly online washing. Furthermore, the application of compressor hand cleaning, online and offline washing during shutdown resulted to a pressure of 8.8 bar against the design value of 9.4 bar. It is reasonable to say that although online water washing yielded a meaningful result but a combination of compressor hand cleaning during shutdown, online and offline washing resulted to a better performance. 


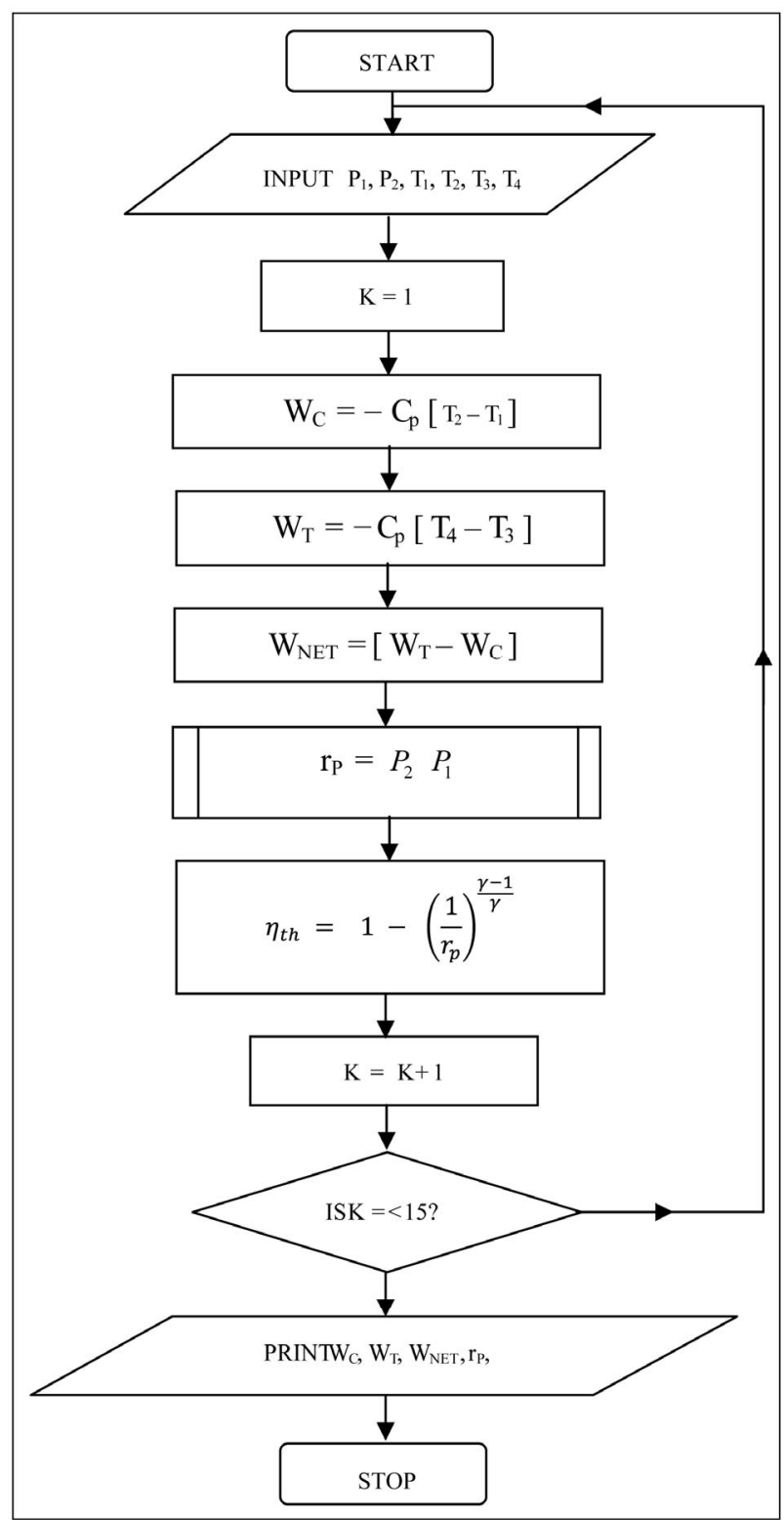

Figure 3. Flow chart for performance trending drawn from Equations (6), (8) and (17).

The path of the GTs when the turbine inlet temperature is plotted against date in weeks is shown in Figure 5. The trend shows that the use of online water washing improved the firing temperature of GT1 but a combination of online and offline water washing resulted in an increase in the firing temperature of $1900 \mathrm{k}$ for GT2.

The graphs of the GTs when the Network output is plotted against date in weeks are shown in Figure 6. It shows that GT1 had initial high network output which later decreased due to redeposition of foulants in the later stages of the compressor. Furthermore, Figure 6 shows that with a combination of compressor hand cleaning, offline and online water washing, the network output of

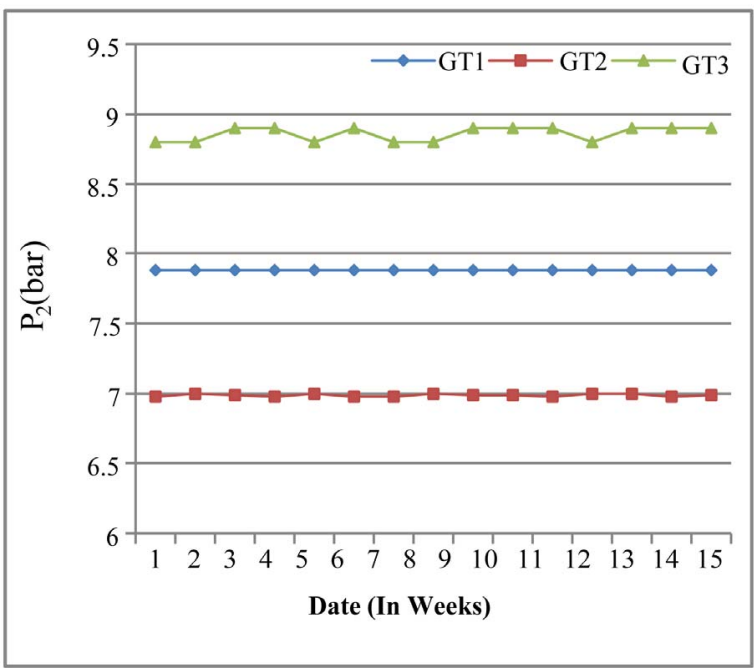

Figure 4. Graph of compressor outlet pressure against date in weeks.

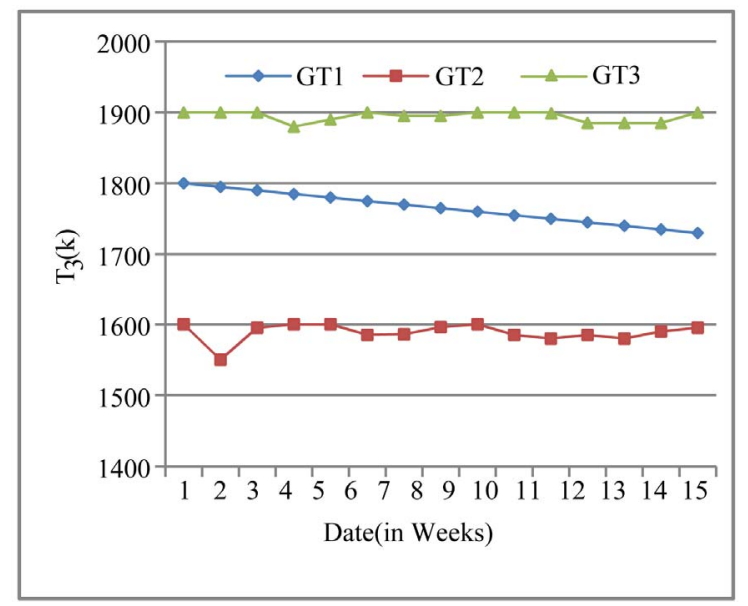

Figure 5. Graph of turbine inlet temperature against date in weeks.

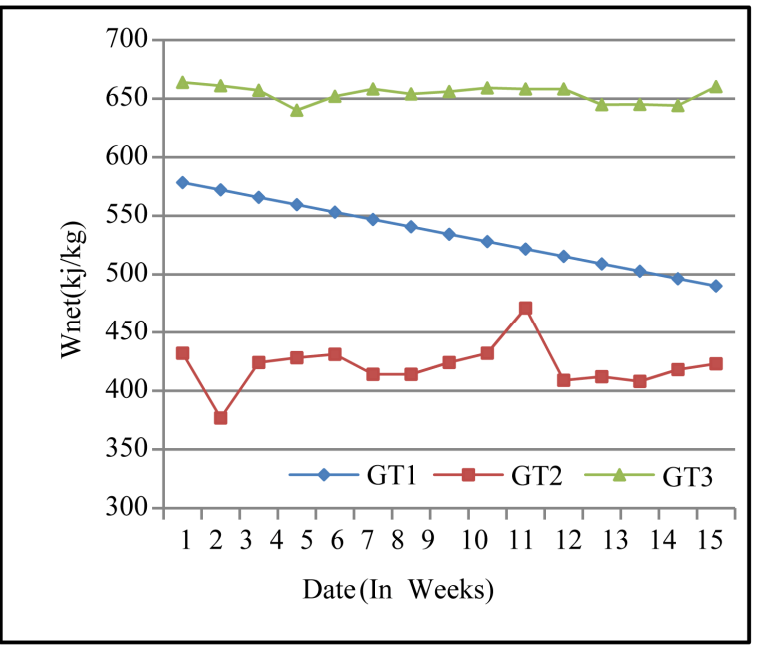

Figure 6. Graph of network against date in weeks. 
Table 1. Monitored Data for GT2 before water-washing $\left(\mathrm{GT}_{0}\right)$.

\begin{tabular}{cccccccccc}
\hline Date (wks) & $\mathbf{T}_{\mathbf{1}}(\mathbf{k})$ & $\mathbf{T}_{\mathbf{2}}(\mathbf{k})$ & $\mathbf{P}_{\mathbf{1}}(\mathbf{b a r})$ & $\mathbf{P}_{\mathbf{2}}(\mathbf{b a r})$ & $\mathbf{T}_{\mathbf{3}} \mathbf{( k )}$ & $\mathbf{T}_{\mathbf{4}}(\mathbf{k})$ & $\mathbf{W}_{\text {net }}(\mathbf{k J} / \mathbf{k g})$ & $\boldsymbol{\eta}_{\mathbf{0}}$ & $\boldsymbol{\eta}_{\mathbf{c}}$ \\
\hline 1 & 300 & 520.7246 & 1.013 & 6.98 & 1600 & 950 & 432.15 & 0.392 & 0.78 \\
2 & 300 & 521.5418 & 1.013 & 7.00 & 1550 & 954 & 376.88 & 0.393 & 0.77 \\
3 & 300 & 520.7211 & 1.013 & 6.99 & 1595 & 953 & 424.11 & 0.392 & 0.76 \\
4 & 300 & 520.7246 & 1.013 & 6.98 & 1600 & 954 & 428.13 & 0.392 & 0.78 \\
5 & 300 & 521.5480 & 1.013 & 7.00 & 1600 & 950 & 431.15 & 0.393 & 0.78 \\
6 & 300 & 520.7246 & 1.013 & 6.98 & 1585 & 953 & 414.06 & 0.392 & 0.77 \\
7 & 300 & 520.2246 & 1.013 & 6.98 & 1586 & 954 & 414.06 & 0.392 & 0.77 \\
8 & 300 & 521.5480 & 1.013 & 7.00 & 1596 & 953 & 424.11 & 0.393 & 0.76 \\
9 & 300 & 520.7211 & 1.013 & 6.99 & 1600 & 950 & 432.15 & 0.392 & 0.78 \\
10 & 300 & 520.7211 & 1.013 & 6.99 & 1585 & 950 & 471.08 & 0.392 & 0.76 \\
11 & 300 & 520.7246 & 1.013 & 6.98 & 1580 & 953 & 409.04 & 0.392 & 0.76 \\
12 & 300 & 521.5480 & 1.013 & 7.00 & 1585 & 954 & 412.05 & 0.393 & 0.77 \\
13 & 300 & 521.5480 & 1.013 & 7.00 & 1580 & 953 & 408.03 & 0.393 & 0.78 \\
14 & 300 & 520.7246 & 1.013 & 6.98 & 1590 & 954 & 418.08 & 0.392 & 0.78 \\
15 & 300 & 520.7211 & 1.013 & 6.99 & 1595 & 954 & 423.11 & 0.392 & 0.77 \\
\hline
\end{tabular}

Table 2. Monitored data for GT1 with online water-washing.

\begin{tabular}{cccccccccc}
\hline Date (wks) & $\mathbf{T}_{\mathbf{1}}(\mathbf{k})$ & $\mathbf{T}_{\mathbf{2}}(\mathbf{k})$ & $\mathbf{P}_{\mathbf{1}}(\mathbf{b a r})$ & $\mathbf{P}_{\mathbf{2}}(\mathbf{b a r})$ & $\mathbf{T}_{\mathbf{3}}(\mathbf{k})$ & $\mathbf{T}_{\mathbf{4}}(\mathbf{k})$ & $\mathbf{W}_{\text {net }}(\mathbf{k J} / \mathbf{k g})$ & $\boldsymbol{\eta}_{\mathbf{0}}$ & $\boldsymbol{\eta}_{\mathbf{c}}$ \\
\hline 1 & 300 & 541.1492 & 1.013 & 7.88 & 1800 & 983.2679 & 578.46082 & 0.457 & 0.82 \\
2 & 300 & 550.1683 & 1.013 & 7.88 & 1795 & 977.8053 & 572.14150 & 0.457 & 0.82 \\
3 & 300 & 559.1875 & 1.013 & 7.88 & 1790 & 975.0740 & 565.82224 & 0.457 & 0.81 \\
4 & 300 & 568.2066 & 1.013 & 7.88 & 1785 & 972.3427 & 559.50295 & 0.457 & 0.82 \\
5 & 300 & 577.2258 & 1.013 & 7.88 & 1780 & 969.6114 & 553.18366 & 0.457 & 0.82 \\
6 & 300 & 586.2449 & 1.013 & 7.88 & 1775 & 966.8801 & 546.86496 & 0.457 & 0.81 \\
7 & 300 & 595.2641 & 1.013 & 7.88 & 1770 & 964.1488 & 540.54507 & 0.457 & 0.81 \\
8 & 300 & 604.2832 & 1.013 & 7.88 & 1765 & 961.4175 & 534.22572 & 0.457 & 0.81 \\
9 & 300 & 613.3024 & 1.013 & 7.88 & 1760 & 958.6862 & 527.90649 & 0.457 & 0.81 \\
10 & 300 & 622.3215 & 1.013 & 7.88 & 1755 & 955.9541 & 521.58719 & 0.457 & 0.82 \\
11 & 300 & 631.3407 & 1.013 & 7.88 & 1750 & 953.2236 & 515.2679 & 0.457 & 0.81 \\
12 & 300 & 640.3598 & 1.013 & 7.88 & 1745 & 953.2236 & 508.94861 & 0.457 & 0.82 \\
13 & 300 & 649.3790 & 1.013 & 7.88 & 1740 & 950.4923 & 502.62932 & 0.457 & 0.82 \\
14 & 300 & 658.3982 & 1.013 & 7.88 & 1735 & 949.7620 & 496.31002 & 0.457 & 0.82 \\
15 & 300 & 667.4173 & 1.013 & 7.88 & 1730 & 945.0297 & 489.99073 & 0.457 & 0.82 \\
\hline
\end{tabular}

Table 3. Monitored data for GT2 during a combination of compressor hand cleaning, online and offline water-washing.

\begin{tabular}{|c|c|c|c|c|c|c|c|c|c|}
\hline Date (wks) & $\mathbf{T}_{1}(\mathbf{k})$ & $\mathbf{T}_{2}(\mathbf{k})$ & $\mathbf{P}_{1}$ (bar) & $\mathbf{P}_{2}$ (bar) & $\mathbf{T}_{3}(\mathbf{k})$ & $\mathbf{T}_{4}(\mathbf{k})$ & $W_{\text {net }}(\mathbf{k J} / \mathbf{k g})$ & $\eta_{0}$ & $\eta_{\mathrm{c}}$ \\
\hline 1 & 300 & 556.36 & 1.013 & 8.80 & 1900 & 983 & 663.943 & 0.4608 & 0.85 \\
\hline 2 & 300 & 556.36 & 1.013 & 8.80 & 1900 & 986 & 660.923 & 0.4608 & 0.85 \\
\hline 3 & 300 & 558.16 & 1.013 & 8.90 & 1900 & 988 & 657.109 & 0.4625 & 0.85 \\
\hline 4 & 300 & 558.16 & 1.013 & 8.90 & 1880 & 985 & 640.024 & 0.4625 & 0.85 \\
\hline 5 & 300 & 556.36 & 1.013 & 8.80 & 1890 & 985 & 651.883 & 0.4608 & 0.83 \\
\hline 6 & 300 & 558.16 & 1.013 & 8.90 & 1900 & 987 & 658.114 & 0.4625 & 0.84 \\
\hline 7 & 300 & 556.36 & 1.013 & 8.80 & 1895 & 988 & 653.893 & 0.4608 & 0.84 \\
\hline 8 & 300 & 556.36 & 1.013 & 8.80 & 1895 & 986 & 655.903 & 0.4608 & 0.85 \\
\hline 9 & 300 & 558.16 & 1.013 & 8.90 & 1900 & 986 & 659.119 & 0.4625 & 0.85 \\
\hline 10 & 300 & 558.16 & 1.013 & 8.90 & 1900 & 987 & 658.114 & 0.4625 & 0.85 \\
\hline 11 & 300 & 558.16 & 1.013 & 8.90 & 1900 & 987 & 658.114 & 0.4625 & 0.85 \\
\hline 12 & 300 & 556.36 & 1.013 & 8.80 & 1885 & 987 & 644.848 & 0.4608 & 0.85 \\
\hline 13 & 300 & 558.16 & 1.013 & 8.90 & 1885 & 985 & 645.049 & 0.4625 & 0.85 \\
\hline 14 & 300 & 558.16 & 1.013 & 8.90 & 1885 & 986 & 644.044 & 0.4625 & 0.85 \\
\hline 15 & 300 & 558.16 & 1.013 & 8.90 & 1900 & 985 & 660.124 & 0.4625 & 0.85 \\
\hline
\end{tabular}


Table 4. Values of percentage derivation in compressor outlet pressure under various operational practices.

\begin{tabular}{|c|c|c|c|c|c|c|c|c|c|}
\hline \multirow{2}{*}{$\begin{array}{l}\text { Date } \\
\text { (wks) }\end{array}$} & \multicolumn{3}{|c|}{ P2 (bar) GT1 } & \multicolumn{3}{|c|}{ P2 (bar) GT2 } & \multicolumn{3}{|c|}{ P2 (bar) GT3 } \\
\hline & $\begin{array}{c}\text { Design } \\
\text { Value }\end{array}$ & $\begin{array}{c}\text { Operational } \\
\text { Value }\end{array}$ & $\% D$ & $\begin{array}{l}\text { Design } \\
\text { Value }\end{array}$ & $\begin{array}{c}\text { Operational } \\
\text { Value }\end{array}$ & $\% D$ & $\begin{array}{c}\text { Design } \\
\text { Value }\end{array}$ & $\begin{array}{c}\text { Operational } \\
\text { Value }\end{array}$ & $\% D$ \\
\hline 1 & 9.40 & 6.98 & -25.74 & 9.40 & 7.88 & -16.17 & 9.40 & 8.80 & -6.38 \\
\hline 2 & 9.40 & 7.00 & -25.53 & 9.40 & 7.88 & -16.17 & 9.40 & 8.80 & -6.38 \\
\hline 3 & 9.40 & 6.99 & -25.64 & 9.40 & 7.88 & -16.17 & 9.40 & 8.90 & -5.32 \\
\hline 4 & 9.40 & 6.98 & -25.74 & 9.40 & 7.88 & -16.17 & 9.40 & 8.90 & -5.32 \\
\hline 5 & 9.40 & 7.00 & -25.53 & 9.40 & 7.88 & -16.17 & 9.40 & 8.80 & -6.38 \\
\hline 6 & 9.40 & 6.98 & -25.74 & 9.40 & 7.88 & -16.17 & 9.40 & 8.90 & -5.32 \\
\hline 7 & 9.40 & 6.98 & -25.74 & 9.40 & 7.88 & -16.17 & 9.40 & 8.80 & -6.38 \\
\hline 8 & 9.40 & 7.00 & -25.53 & 9.40 & 7.88 & -16.17 & 9.40 & 8.80 & -6.38 \\
\hline 9 & 9.40 & 6.99 & -25.64 & 9.40 & 7.88 & -16.17 & 9.40 & 8.90 & -5.32 \\
\hline 11 & 9.40 & 6.98 & -25.74 & 9.40 & 7.88 & -16.17 & 9.40 & 8.90 & -5.32 \\
\hline 12 & 9.40 & 7.00 & -25.53 & 9.40 & 7.88 & -16.17 & 9.40 & 8.80 & -6.38 \\
\hline 13 & 9.40 & 7.00 & -25.53 & 9.40 & 7.88 & -16.17 & 9.40 & 8.90 & -5.32 \\
\hline 14 & 9.40 & 6.98 & -25.74 & 9.40 & 7.88 & -16.17 & 9.40 & 8.90 & -5.32 \\
\hline 15 & 9.40 & 6.99 & -25.64 & 9.40 & 7.88 & -16.17 & 9.40 & 8.90 & -5.32 \\
\hline
\end{tabular}

GT2 increased to $480.0 \mathrm{~kJ} / \mathrm{kg}$.

The graph of compressor efficiency is shown in Figure 7. From the graph, GT2 has the highest compressor efficiency of $85 \%$. This is as a result of a combination of compressor hand cleaning and offline/online water washing. Also, GT1 yielded compressor efficiency of $82 \%$ as a result of applying online water washing only. It also implies that the air pumping capacity of the GT2 compressor has increased.

The graph of overall GTs operational efficiency is shown in Figure 8. It is observed that a small change of the compressor efficiency have a significant effect on theoverall GT performance and efficiency. GT1 has com-

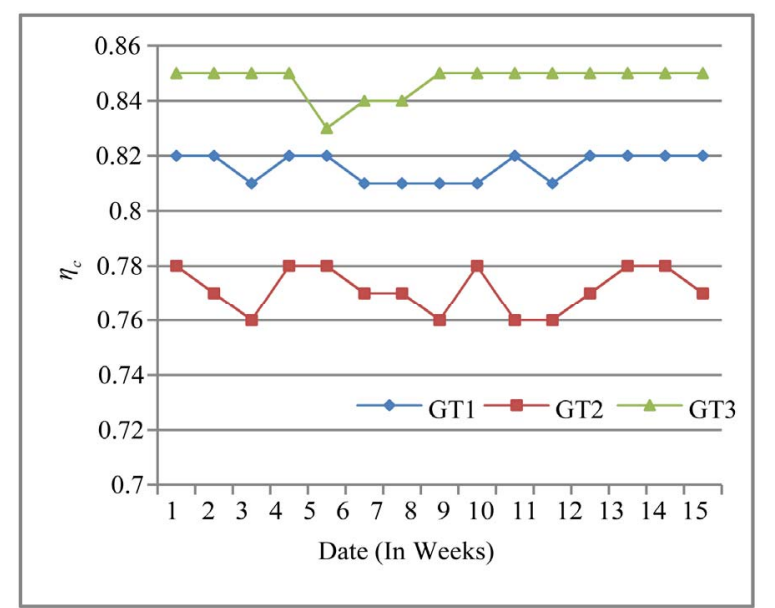

Figure 7. Graph of isotropic compressor outlet efficiency against date in weeks

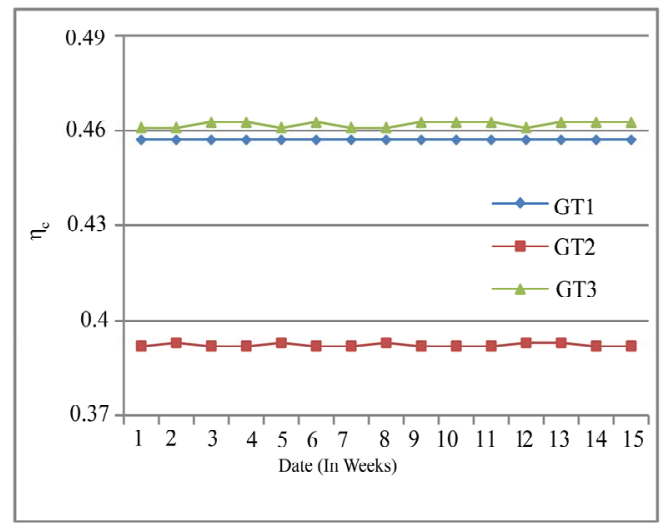

Figure 8. Graph of overall operational efficiency against date in weeks.

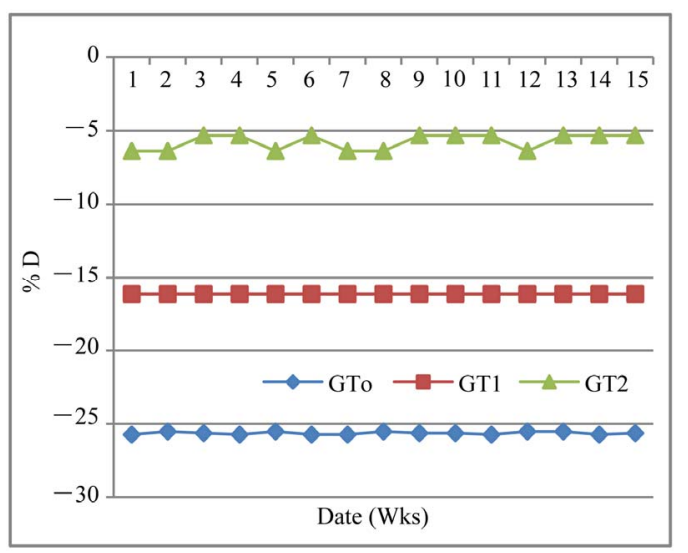

Figure 9. Percentage deviation in compressor outlet against date in weeks. 
pressor efficiency of $82 \%$ which resulted to overall GT efficiency of $45.8 \%$. Also, GT2 has compressor efficiency of $85 \%$ and it resulted to overall operational efficiency of $46.25 \%$.

Also, the graph of percentage derivation in compressor outlet pressure against date in weeks is shown in Figure 9(a).

\section{Conclusions}

A comparative analysis has been carried out on three GTs on industrial duty for electricity generation. These GTs were commissioned at the same time before the research was carried out on them. GTo served as a control while compressor online washing was applied on GT1, a combination of compressor hand cleaning and online/offline water washing was applied to GT2. The exercise lasted for fifteen weeks. The result of the analysis shows that with the use of compressor online water washing on GT1 yielded a compressor efficiency of $82 \%$ and overall operational efficiency of $45.8 \%$. Also, the use of compressor hand cleaning, online and offline water washing on GT2 yielded a compressor efficiency of $85 \%$ and overall operational efficiency of $46.25 \%$ the results are handy to conclude that an acceptable balance between these maintenance and operational practices improves the GTs performance and optimize their availability.

\section{References}

[1] I. S. Diakunchak, "Performance Degradation in Industrial Gas Turbines,” ASME Paper 91-GT-228, 1991.

[2] P. C. Frith, "The Effect of Compressor Rotor Tip Crops on Turbo- Engine Performance,” ASME Paper 92-GT-83, 1992.

[3] S. A. Khalid, A. S. Khalsa, I. I. A. Waitz, S. C. Tan, E. M. Greitzer, N. A. Cumpsty, J. J. Adamczyk and F. E. Marble, "Endwal Blockage in Axial Compressor," ASME Paper 98-GT-203,1998.

[4] R. J. Kind, P. J. Serjak and M. W. P. Abbott, "Measurements and Prediction of the Effects of Surface Roughness on Profile Losses and Deviation in a Turbine Cascade,” ASME Paper 96-GT-203, 1996.

[5] R. Kurz and K. Brun, "Degradation in Gas Turbine Systems,” ASME Journal of Engineering for Gas Turbines and Power, Vol. 123, No. 1, 2001 pp. 70-77. doi:10.1115/1.1340629

[6] R. K. Rajput, “A Textbook of Power Plant Engineering,” Laximi Publications, New Delhi, 1995.

[7] D. G. Wilson, "The Design of High Efficiency Turbomachinery and Gas Turbines,” MIT Press, Mass, 1994.

[8] T. D. Eastop and A. McConkey "Applied Thermodynamics for Engineering Technologists,” 5th Edition, Addi-
son-Wesley Longman, Ltd., UK, 1993.

[9] P. K. Nag, "Power Plant Engineering," 2nd Edition, Tata McGraw Hill Publishing Company Limited, New Delhi, 2001, p.764.

[10] E. A. Ogbonnaya, "Modeling Vibration Based Faults in Rotor Shaft of Gas Turbines,” Ph.D Thesis, Rivers State University of Science and Technology, Port Harcourt, 2004.

[11] E. Schneider, Dermiricioglu, S. Fraanco and D. Therkom, "Analysis of Compressor Online Washing to Optimize Gas Turbine Power Plant Performance,” Proceedings of ASME Turbo Expo 2009, Orlando, 8-12 June 2009, pp. 1-9.

[12] E. A. Ogbonnaya and K. Theophilus Johnson, "Use of Multiple Variable Mathematical Method for Effective Condition Monitoring of Gas Turbine," Proceedings of ASME Turbo-Expo, Glasgow, 14-18 June 2010, pp. 1-4.

[13] R. J. Boyle, "Prediction of Surface Roughness and Incidence Effects on Turbine Performance," Journal of Turbomachinery, Vol. 116, No. 4, 1994, pp. 512-519. doi:10.1115/1.2929468

[14] E. A. Ogbonnaya, H. U. Ugwu and C. N. Johnson, "Computer-Aided Solution to the Vibrational Effect of Instabilities in Gas Turbine Compressors,” Engineering, Vol. 2, No. 8, 2010, pp. 658-664. doi:10.4236/eng.2010.28084

[15] R. Beebe, "Condition Monitoring by Performance Analysis to Optimize Time for Overhaul of Centrifugal Pumps," 52nd Annual Meeting for Machinery Failure Prevention Society, Virginia Beach, 3 August 2009, pp. 102-112.

[16] C. B. Meher-Homji, M. Chaka and A. E. Brouley, "The Fouling of Axial Flow Compressor-Causes,Effects, Susceptibility and Sensitivity,” Proceedings of ASME Turbo Expo Orlando, Florida, 8-12 June 2009, pp. 1-20. www.teurbexpo.org

[17] M. Venturini, "Influence of Blade Determination on Compressor and Turbine Performance” ASME Paper GT 2008-50043, 2008.

[18] R. E. Duudas, "The Use of Performance Monitoring to Prevent Compressor and Turbine Failures," ASME Intentional Gas Turine and Aeroengine Congress, Paper No. 82-GT-66, 1982.

[19] E. D. Bently, C. T. Hatch and B. Grissom "Fundamental of Rotating Machine Diagnositic,” Bently Pressurized Bearing Press, Minden, 2002.

[20] E. A. Ogbonnaya, "Diagnosing and Prognosing Gas Turbine Rotor Shaft Faults Using the MICE,” Proceedings of ASME Turbo Expo GT 2009-59450, Orlando, 8-12 June 2009, pp. 1-10.

[21] H. C. Pussey, “Turbo-Machinery Condition Monitoring and Failure Prognosis, Shock and Vibration Information Analysis," centre/H1-Test Laboratories, Proceedings of Institute of Vibration, Virginia, 8 November 2007, pp 2-10.

[22] M. P. Boyce and F. Gonzales, “A Study of Online and Offline Turbine Washing to Optimize the Operation of a 
Gas Turbine," Journal of Engineering for Gas Turbine and Power, Vol. 129, No. 1, 2007, pp. 114-129. doi:10.1115/1.2181180

[23] J. P. Stalder, "Gas Turbine Compressor Washing State of the Art: Field Experiences, Journal of Engineering for Gas Turbine and Power, Vol. 123, No. 2, 2001, pp 363-370. doi:10.1115/1.1361108

\section{Nomenclature}

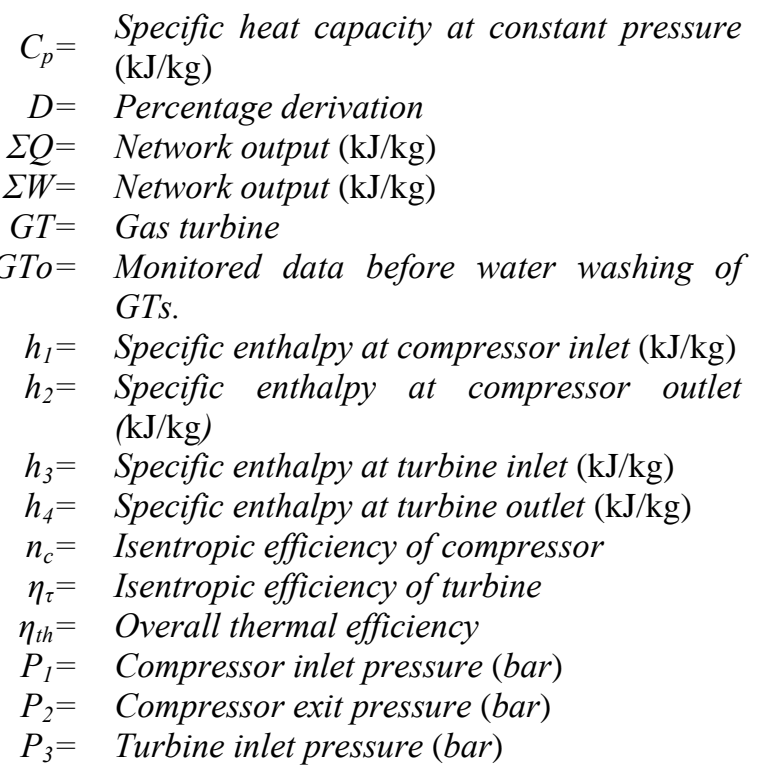

[24] S. Demircioglu, "Detail Analysis of Compressor Online Wash Impact in the Gas Turbine Performance,” Diploma Thesis, F. H. Offenbury, 2008.

[25] K. R. Brun and H. Simmons, “Aerodynamic Instability and Life Limiting Effects of Inlet and Interstage Water Injection into Gas Turbines," ASME Paper GT 2005-68007, 2005.
$P_{4}=$ Turbine outlet pressure (bar)

$Q_{\text {in }}=$ Heat input $(\mathrm{kJ} / \mathrm{kg})$

$Q_{\text {out }}=$ Heat output $(\mathrm{kJ} / \mathrm{kg})$

$\gamma_{p}=$ Pressure ratio

$T_{1}=$ Compressor inlet temperature $(\mathrm{k})$

$T_{2}=$ Compressor outlet temperature $(\mathrm{k})$

$T_{2}^{l}=$ Compressor isentropic outlet temperature (k)

$T_{3}=$ Turbine inlet temperature $(\mathrm{k})$

$T_{4}=$ Turbine outlet temperature $(\mathrm{k})$

$T_{4}{ }^{l}=$ Turbine isentropic outlet temperature $(\mathrm{k})$

$W c=$ Compressor work $(\mathrm{kJ} / \mathrm{kg})$

$W_{T}=$ Turbine work $(\mathrm{kJ} / \mathrm{kg})$ 